\title{
Surgical Treatment of Advanced Gastric Cancer: Japanese Perspective
}

\author{
M. Sasako M. Saka T. Fukagawa H. Katai T. Sano
}

Gastric Surgery Division, National Cancer Center Hospital, Tokyo, Japan

\section{Key Words}

Esophagogastric junction • Gastric cancer, advanced •

Surgical treatment

\begin{abstract}
The results of clinical trials regarding surgery of curable advanced gastric cancer and esophagogastric junction (EGJ) tumors are reviewed and summarized. Four clinical trials have evaluated D2 dissection for curable gastric cancer in the West. Two large trials in the UK and the Netherlands failed to prove the efficacy of D2 dissection. However, these trials had critical weak points. As they were carried out in a number of hospitals where there was no experience with this surgery, the quality of surgery and postoperative care were very poor making the hospital mortality unacceptably high. After these trials, an Italian group started a phase II study in 8 hospitals with a relatively high volume to confirm the safety of this procedure for Caucasians. They achieved $3 \%$ mortality, which was much smaller than that of even D1 in the former trials. These results first highlighted the importance of learning and hospital volume in D2 dissection. Survival results of the Dutch trial showed some difference between D1 and D2, but the difference was not statistically significant. This was attributed to the high hospital mortality and poor quality of surgery, especially low compliance of D2 and the high rate of extension of D1, making this comparison similar to that between D1.3 and D1.7. The results of
\end{abstract}

the phase III study by the Italian group are awaited. Recently a Taiwanese trial proved the benefit of D2 dissection over D1 in a phase III trial. This was a single institutional trial with a sample size of 221 patients. The 5 -year survival rate of $D 2$ and D1 was 59.5 and $53.6 \%$, respectively $(p=0.04)$. The Dutch trials for EGJ tumors showed a large difference in overall survival between the transthoracic and transhiatal approach for Siewert type 1 and 2 tumors, but this was not statistically significant, most likely due to the small sample size. In the subgroup analysis, they demonstrated that there was no survival difference in Siewert type 2 but a large difference in Siewert type 1. A Japanese study showed that there is no benefit to the thoraco-abdominal approach over the transhiatal approach for EGJ tumors whose invasion in the esophagus is $3 \mathrm{~cm}$ or less. These two trials clearly demonstrated that mediastinal dissection through a right thoracotomy is recommendable for Siewert type 1, while the transhiatal approach should be considered as standard for Siewert type 2.

Copyright $\odot 2007$ S. Karger AG, Basel

\section{Background}

In the guidelines of the Japan Gastric Cancer Association, standard surgery for curable advanced gastric cancer is defined as a more than $2 / 3$ gastrectomy with D2 dissection [1]. With the results of several important

\section{KARGER \\ Fax +41613061234 E-Mail karger@karger.ch} www.karger.com

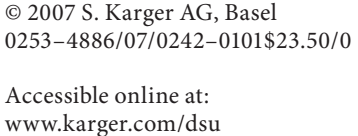

Dr. M. Sasako

National Cancer Center

5-1-1, Tsukiji

Chuo-ku, Tokyo 1040045 (Japan)

Tel. +81 33542 2511, Fax +8133547 6611, E-Mail msasako@gan2.ncc.go.jp 
Table 1. Morbidity and mortality after D2 dissection and hospital volume

\begin{tabular}{llcccll}
\hline Trial & Type & $\mathrm{n}$ & $\begin{array}{l}\text { Number of patients } \\
\text { per hospital per year }\end{array}$ & $\begin{array}{l}\text { Mortality } \\
\%\end{array}$ & $\begin{array}{l}\text { Morbidity } \\
\%\end{array}$ & Reference \\
\hline Hong Kong & RCT & 30 & 7.5 & 3 & 57 & Robertson et al. [7] \\
MRC & RCT & 200 & 1.5 & 13 & 46 & Cuschieri et al. [8] \\
Dutch & RCT & 331 & 1.0 & 10 & 43 & Bonenkamp et al. [2] \\
Taiwanese & RCT & 211 & 18.5 & 0 & 17 & Wu et al. [16] \\
IGCSG & Phase II & 191 & 8.0 & 3 & 21 & Degiuli et al. [4] \\
IGCSG & RCT & 82 & 4.3 & 0 & 16 & Degiuli et al. [6] \\
Italian study & Retro & 451 & 21.5 & 2 & 17 & Roviello et al. [9] \\
\hline
\end{tabular}

RCT $=$ Randomized controlled trial; $\mathrm{MRC}=$ Medical Research Council; IGCSG = Italian Gastric Cancer Study Group.

clinical trials, not only in surgery but also multidisciplinary treatment, this policy of the Japanese guidelines might be challenged. In this article, the Japanese perspective of curative surgery for advanced gastric cancer is explained.

\section{Results of European Trials}

There have been four European clinical trials on D2 dissection for curable gastric cancer [2-5]. Three of them were phase III trials and the remainder was the only phase II trial in the world. The phase III trials were carried out by the Medical Research Council (MRC) [3], the Dutch Gastric Cancer Group (DGCG) [2] and the Italian Gastric Cancer Study Group (IGCSG) [5]. The first two trials have already shown negative results, while the long-term results of the last one are awaited. After the first two large phase III trials showed quite high hospital mortality after D2 dissection on Caucasians, the IGCSG started with a phase II study to confirm the safety of the D2 dissection in their population [4].

\section{Morbidity and Mortality of D2 Dissection in}

These Trials

The Dutch and the MRC studies showed extremely high hospital mortality after D2 dissection, 10 and 13\%, respectively. Such a high mortality is no longer accepted for any cancer surgery today. These results were heavily criticized and attributed to a very low hospital volume [6]. Table 1 shows the clear negative correlation between hospital volume and hospital mortality after D2 dissection in the literature. This high mortality was also attributed to splenectomy and pancreatectomy. Especially in the
MRC trial, many surgeons thought that D2 distal gastrectomy included splenectomy, and splenectomy was carried out in many distal gastrectomy cases [10]. This was based on the misunderstanding of the definition of $\mathrm{D} 2$ gastrectomy by the Japanese Research Society for Gastric Cancer [11]. In Japan, splenectomy was included in D2 dissection only when a total gastrectomy was carried out. Together with thorough lymph node dissection of the lesser curvature, splenectomy causes serious ischemia of the remnant stomach, necrosis of the remnant stomach or anastomotic leakage. This was also the case in the DGCG trial [12]. In the multivariate analysis of hospital mortality, splenectomy was one of the factors most responsible for mortality. The lack of experience in treating major surgical complications after D2 dissection, namely, anastomotic leakage, pancreatic fistula (juice leak) or intra-abdominal abscess, led to a much higher mortality than a Japanese specialist center where a few hundred patients were treated yearly (table 2) [6]. With less than a few cases yearly, surgeons can never learn how to treat these major complications to avoid treatment-related death. This high mortality after D2 dissection in the Dutch trial might also be attributed to the greater fragility of the Dutch compared with the Japanese. However, the results of another Dutch trial comparing a transthoracic esophagogastrectomy via right thoracotomy with a transhiatal approach for esophagogastric junction (EGJ) tumors showed a much lower mortality in the both treatment arms, $4 \%$ for the former and $2 \%$ for the latter [13]. This trial was carried out exclusively in two major cancer hospitals which have a reasonably high hospital volume. This suggests that high mortality in the D1/D2 trial was not attributed to the fragility of the Dutch patients but to the very low hospital volume. 
Table 2. Mortality after postoperative major surgical complications

\begin{tabular}{|c|c|c|c|c|c|c|c|}
\hline \multirow[t]{2}{*}{ Complication } & \multicolumn{3}{|c|}{ Dutch trial $(\mathrm{n}=711)$} & \multicolumn{3}{|c|}{ NCCH trial $(1982-1987 ; \mathrm{n}=1,197)$} & \multirow[t]{2}{*}{$\mathrm{p}$} \\
\hline & $\begin{array}{l}\text { deceased } \\
\text { patients }\end{array}$ & $\begin{array}{l}\text { affected } \\
\text { patients }\end{array}$ & $\%$ & $\begin{array}{l}\text { deceased } \\
\text { patients }\end{array}$ & $\begin{array}{l}\text { affected } \\
\text { patients }\end{array}$ & $\%$ & \\
\hline Leakage & 19 & 46 & 41.3 & 12 & 84 & 14.3 & 0.0005 \\
\hline Distal & 9 & 22 & 40.1 & 2 & 23 & 8.7 & 0.012 \\
\hline Total & 10 & 24 & 41.7 & 10 & 60 & 16.7 & 0.0047 \\
\hline Abscess or pancreatic fistula & 19 & 91 & 20.9 & 2 & 75 & 2.7 & 0.0004 \\
\hline
\end{tabular}

$\mathrm{NCCH}=$ National Cancer Center Hospital.

After these two trials with dismal short-term results, the IGCSG started a phase II trial to confirm the safety. Actually a 3\% mortality was found in 8 hospitals with a total of 191 patients [4]. They avoided the routine use of distal pancreatectomy in cases of total gastrectomy; instead they adopted pancreas-preserving total gastrectomy, the so-called Maruyama technique [5]. Thus they avoided splenectomy in distal gastrectomy and distal pancreatectomy in total gastrectomy. The morbidity and mortality shown by the phase II study was confirmed by the results of the interim analysis of the IGCSG phase III trial. Hospital mortality was $1.3 \%$ after D1 but $0 \%$ after D2 gastrectomy in this study [6].

\section{Survival Results after D2 Dissection}

In the MRC trial, the survival curve of D2 was never better than that of D1 until the end of the trial. In the Dutch trial, the survival curve of D2 caught up with that of D1 after 4 years and remained superior, but the difference between D1 and D2 survival never reached statistical significance. Practically, in the MRC trial, there was no quality control of surgery and the quality seemed poor due to the mortality. In the Dutch trial, there were several efforts to control the quality of performance including direct tuition of the $\mathrm{D} 2$ dissection in the operation theater and quality evaluation by the number of dissected nodes. According to their results, there were many cases in the $\mathrm{D} 1$ group where more extended dissection than D1 was actually carried out and many patients in the D2 group underwent less than D2 dissection [14]. Eventually they compared D1.3 versus D1.7, for example, minimizing the difference between the arms. Low-quality surgery together with a much higher mortality immediately after surgery could explain why D2 dissection was not found to be beneficial. In fact, the Italian group showed much better survival results in their phase II trial than those of the Dutch trial [15]. The 5-year survival rates for stages IA, IB, II, IIIA and IIIB were $93,88,60,40$ and $20 \%$, respectively, while those in the Dutch trial were $81,61,42$, 28 and 13\%, respectively. Survival results of the phase III study by the IGCSG are awaited.

\section{Results of Taiwanese Trial}

Recently a Taiwanese hospital published the results of a phase III study comparing D1 versus D2/3 surgery for curable gastric cancer in a single institution [16]. Their D3 includes lymph node stations in the hepatoduodenal ligament, on the superior mesenteric vein, behind the common hepatic artery and on the posterior pancreatic surface in addition to D2 dissection, according to the 1st English Edition of the Japanese Classification of Gastric Carcinoma [17]. They showed statistically significant improvement in survival by $\mathrm{D} 2 / 3$ surgery over $\mathrm{D} 1$. The 5 year overall survival of D2/3 and D1 was 59.5 and $53.6 \%$, respectively ( $\mathrm{p}=0.04$; fig. 1 ). This study included only three surgeons at a single institution, therefore the quality of surgery in this study seemed to be more identical than in multicenter trials. This is the first randomized controlled study which showed significantly better overall survival of D2/3 surgery than D1 in the world. There are several remarkable differences between this study and the Dutch study. Due to the much higher hospital volume and good quality control at a single institution, the hospital mortality after D2/3 was $0 \%$ in this study, while it was as high as $10 \%$ in the Dutch trial. More patients in the Taiwanese study had antral tumors and underwent distal subtotal gastrectomy than the Dutch trial. The proportion of those who underwent distal subtotal gastrectomy in this study and the Dutch study was 76 and $66 \%$, respectively. Due to the rather small sample size and 
Fig. 1. Overall survival curves of the entire patient population by treatment groups in the Dutch trial.

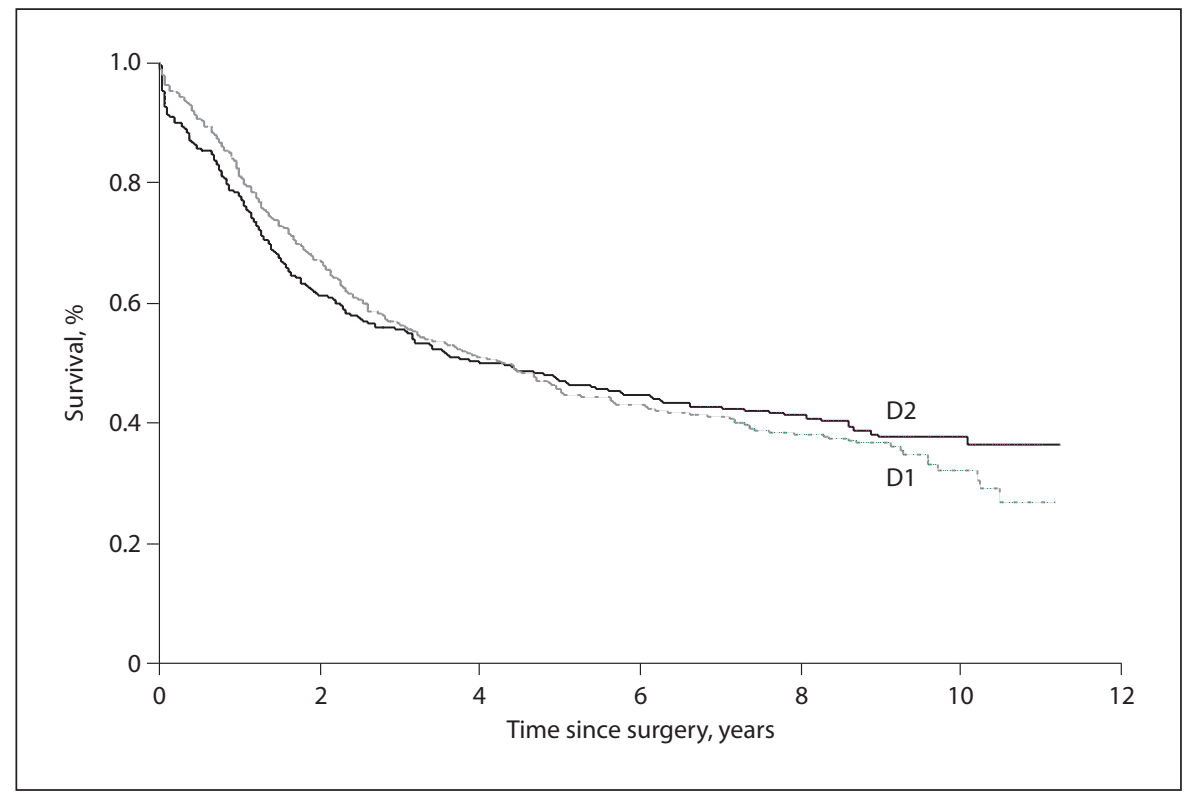

modest survival benefit, this study cannot be considered as solid evidence for the superiority of D2 over D1 dissection.

\section{Results of Adjuvant Chemoradiotherapy}

A phase III study comparing surgery alone with postoperative adjuvant chemoradiotherapy (CRT), the INT0116/SWOG9008, showed a large survival benefit of CRT for curable gastric cancer; the median survival time of surgery alone was 27 months, compared with 36 months for CRT [18]. The hazard ratio for death was 1.35 (95\% CI 1.09-1.66; $\mathrm{p}=0.005)$. In this trial, the tested arm included curative surgery and radiation therapy of $45 \mathrm{~Gy}$ with combination chemotherapy using fluorouracil and leucovorin (5 courses of 5-day continuous infusion, including 2 courses of concomitant administration). However, detailed analysis of the type of surgery revealed that 54 and $36 \%$ of the patients underwent D0 and D1 surgery, respectively, while only $10 \%$ underwent D2 dissection. Although there was no statistically significant interaction between the subgroups divided by the degree of lymph node dissection and the effect of treatment, a benefit from treatment was observed only in the D0 or D1 group in the subset analysis [19]. In the retrospective detailed analysis, the researchers of this study found that surgical undertreatment clearly undermined the survival of patients [20]. Thus this study for the first time proved the efficacy of local control by radiation for gastric cancer and proved that limited surgery alone cannot be sufficient treatment for this cancer.

The patient population enrolled in the test arm of this study was by chance quite similar to the population enrolled in a Japanese clinical trial comparing surgery alone with surgery followed by adjuvant CTX (JCOG9206-2) [21]. Table 3 shows the tumor and patient characteristics of the 2 groups. Most of the prognostic factors, i.e., histological type, tumor location, age, tumor size, and, most important, tumor depth, were reasonably comparable between the groups. Although these 2 groups were the patients of two different trials with two different treatment methods, they are identical and therefore the treatment results are more or less comparable. The 5 -year overall survival was 42 and 61\% in the INT0116 and JCOG92062 , respectively. This suggests strongly that D2 surgery alone might produce better survival than limited surgery followed by CRT and that the effect of adjuvant CTX might not be expected after D2 as suggested by the subgroup analysis.

\section{Surgical Treatment for Esophagogastric Junction Tumors}

Hulscher et al. [13] reported the results of a phase III trial for Siewert type 1 and 2 tumors, comparing two surgical approaches, a transthoracic esophagogastrectomy 
Fig. 2. Overall survival curves in patients with Siewert type 1 (a) and Siewert type 2 (b) tumors, by treatment groups. $\mathrm{THO}=$ Transthoracic esophagectomy; TTO = transhiatal esophagectomy.

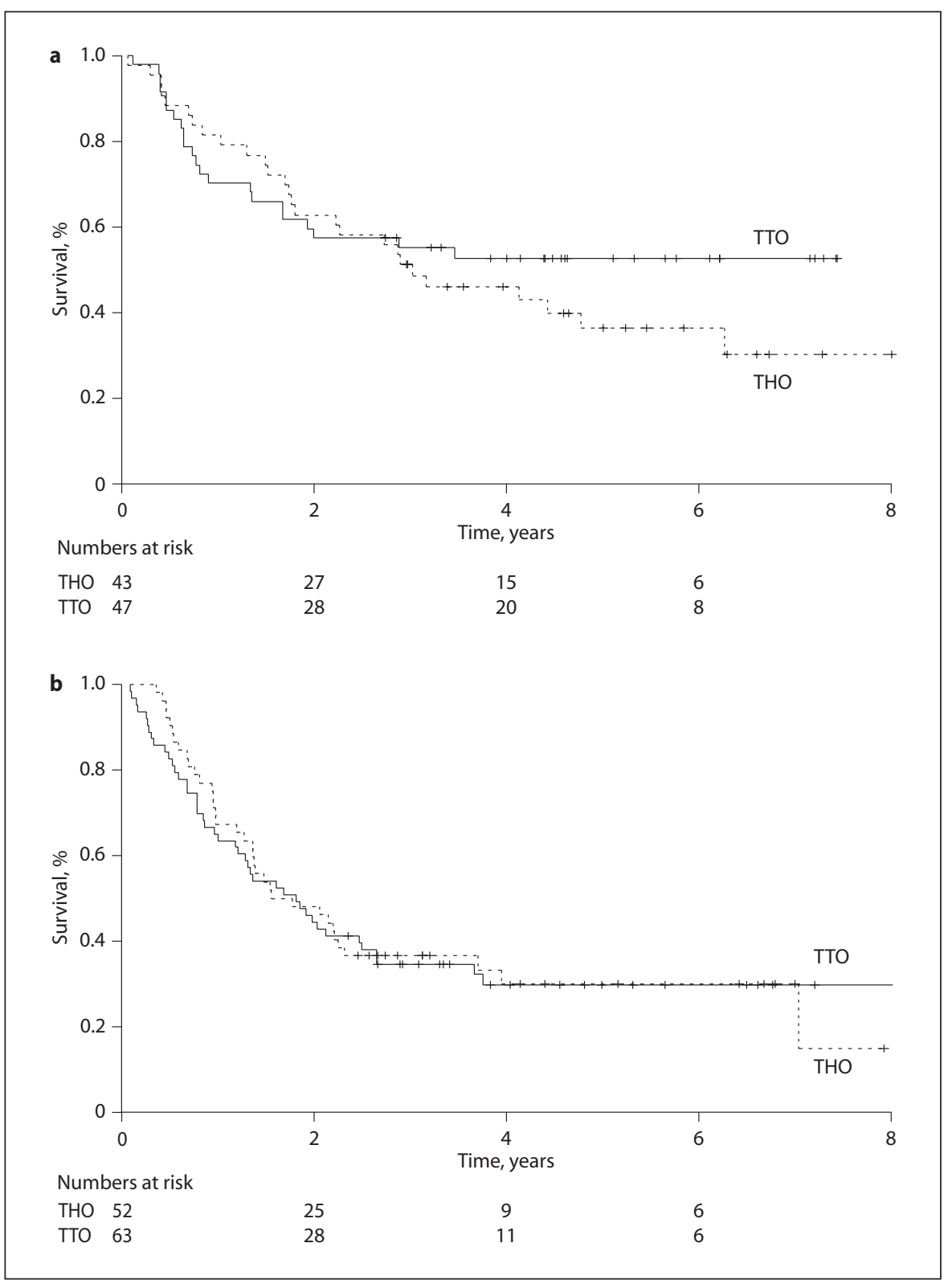

via right thoracotomy with transhiatal one. The overall survival in the entire study population did not show statistically significant differences between the 2 groups. However, the actual difference in the survival curves was impressive and the overall 5-year survival rate was $29 \%$ for the transhiatal approach and 39\% for the transthoracic one ( $\mathrm{p}=0.38$; fig. 1$)$. In the subgroup analysis according to the Siewert classification, the difference in overall 5 -year survival was as large as $17 \%(95 \% \mathrm{CI}-3$ to $37 \%)$ for Siewert type $1(\mathrm{n}=90)$, while it was only $1 \%$ for Siewert type 2 ( $n=115$; fig. 2 ) [22]. Due to the small sam- ple size, this study was not able to show any statistically significant difference, but the results strongly suggest that thorough mediastinal dissection via right thoracotomy is needed for Siewert type 1 but not for type 2 . With higher morbidity after transthoracic dissection, the transhiatal approach might be better treatment for Siewert type 2.

Sasako et al. [23] reported the results of a phase III trial for Siewert type 2 and 3 tumors, comparing a left thoraco-abdominal approach versus a transhiatal one. All these tumors were diagnosed to have esophageal in- 


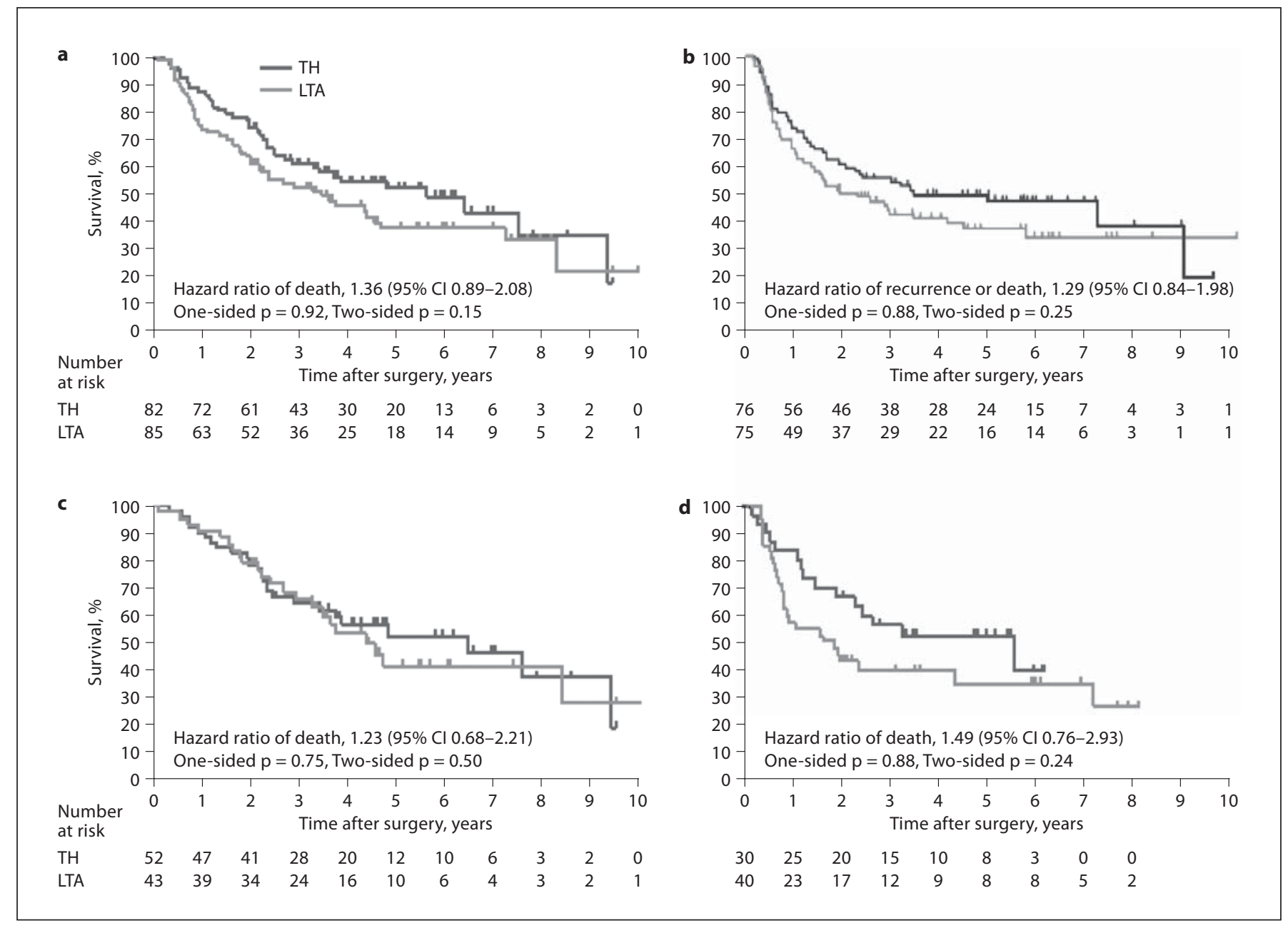

Fig. 3. Overall survival (a) and disease-free survival (b) of the entire patient population and overall survival in patients with Siewert type 2 (c) and type 3 (d) tumors by treatment groups. TH = Transhiatal; LTA = left thoraco-abdominal. Reprinted with permission from The Lancet Oncology [23].

Table 3. Comparison between the INT0116 study and JCOG9206-2 study

\begin{tabular}{|c|c|c|}
\hline & IT0116/SWOG9008 & JCOG9206-2 \\
\hline Surgery $(\mathrm{D} 0 / 1 / 2), \%$ & $54 / 36 / 10$ & $4 / 67 / 33$ \\
\hline Adjuvant & $\operatorname{Rad}(45 \mathrm{~Gy})+\mathrm{CX}(5 \mathrm{FU}+\mathrm{LV})$ & CDDP+5FU+UFT (50\%), none (50\%) \\
\hline Number of patients & 281 (tested arm) & $268($ control $=133$, tested $=135)$ \\
\hline Tumor location & A (53\%), Corp (24\%), cardia (21\%), multifocal (2\%) & L (31\%), M (32\%), U (28\%), wide (9\%) \\
\hline $\mathrm{pT}(\mathrm{T} 1 / \mathrm{T} 2 / \mathrm{T} 3 / \mathrm{T} 4)$ & $14 / 74 / 175 / 18$ & $5 / 87 / 165 / 11$ \\
\hline Proportion of $\mathrm{T} 3 / 4, \%$ & 69 & 66 \\
\hline Node positive, $\%$ & 85 & 72 \\
\hline TRD & $3(1.1 \%)$ & $4(1.5 \%)$ \\
\hline Overall survival ( 5 years), $\%$ & 42 & control 61, tested 62 \\
\hline
\end{tabular}

Rad = Radiation; CX = chemotherapy; LV = leucovorin; 5FU = 5-fluorouracil; CDDP = cis-diamminedichloroplatinum; UFT = uracil-ftegafur; $\mathrm{A}=$ antrum; Corp = gastric body; $\mathrm{L}=$ distal one third; $\mathrm{M}=$ middle one third; $\mathrm{U}=$ upper one third; wide = wide spread; $\mathrm{TRD}=$ treatment-related death. 
vasion of $3 \mathrm{~cm}$ or less. They clearly demonstrated that there was no survival benefit from the left thoraco-abdominal approach which was accompanied by a much higher morbidity and more remarkable deterioration of pulmonary function than the transhiatal approach. The subgroup analysis showed no survival benefit for both Siewert type 2 and 3. Especially for Siewert type 3, the transhiatal approach showed much better survival than the left thoracotomy approach (fig. 3).

From these two trials, the transhiatal approach is regarded as the standard treatment for Siewert type 2 and 3 tumors, while the transthoracic approach via right thoracotomy is recommended for Siewert type 1 tumors.

\section{References}

1 Nakajima T: Gastric cancer treatment guideline in Japan. Gastric Cancer 2002;5:1-5.

-2 Bonenkamp JJ, Hermans J, Sasako M, van De Velde CJ, et al; Dutch Gastric Cancer Group: Extended lymph-node dissection for gastric cancer. N Engl J Med 1999;340:908-914.

$\checkmark 3$ Cuschieri A, Weeden S, Fielding J, Bancewicz J, Craven J, Joypaul V, Sydes M, Fayers $\mathrm{P}$ : Patient survival after $\mathrm{D} 1$ and $\mathrm{D} 2$ resection for gastric cancer: long-term results of the MRC randomized surgical trial. Br J Cancer 1999;79:1522-1530.

-4 Degiuli M, Sasako M, Ponti A, Soldati T, Danese F, Calvo F: Morbidity and mortality after D2 gastrectomy for gastric cancer: results of the Italian Gastric Cancer Study Group prospective multicenter surgical study. J Clin Oncol 1998;16:1490-1493.

-5 Maruyama K, Sasako M, Kinoshita T, Sano T, Katai H, Okabayashi K: Pancreas-preserving total gastrectomy for proximal gastric cancer. World J Surg 1995; 19:532-536.

-6 Degiuli M, Sasako M, Calgaro M, Garino M, Rebecchi F, Mineccia M, Scaglione D, Andreone D, Ponti A, Calvo F: Morbidity and mortality after D1 and D2 gastrectomy for cancer: interim analysis of the Italian Gastric Cancer Study Group (IGCSG) randomised surgical trial. Eur J Surg Oncol 2004;30:303-308.

-7 Robertson CS, Chung SC, Woods SD, et al: a prospective randomized trial comparing R1 subtotal gastrectomy with R3 total gastrectomy for antral cancer. Ann Surg 1994;220: 176-182.

-8 Cuschieri A, Fayers P, Fielding J, Craven J, Bancewicz J, Joypaul V, Cook P; Surgical Cooperative Group: Postoperative morbidity and mortality after D1 and D2 resections for gastric cancer: preliminary results of the MRC randomised surgical trial. Lancet 1996; 347:995-999.
Roviello F, Marrelli D, Morgagni P, de Manzoni G, Di Leo A, Vindigni C, Saragoni L, Tomezzoli A, Kurihara H, Italian Research Group for Gastric Cancer: Survival benefit of extended D2 lymphadenectomy in gastric cancer with involvement of second level lymph nodes: a longitudinal multicenter study. Ann Surg Oncol 2002;9:894-900.

10 Sasako M: Principles of surgical treatment for curable gastric cancer. J Clin Oncol 2003; 21(suppl):274s-275s.

11 Japanese Research Society for the Gastric Cancer: The general rules for the gastric cancer study in surgery and pathology. Jpn J Surg 1981;11:418-425.

12 Sasako M: Risk factors for surgical treatment in the Dutch Gastric Cancer Trial. Br J Surg 1997;84:1567-1571.

13 Hulscher JBF, van Sandick JW, de Boer AGEM, Wijnhoven BPL, Tijssen JGP, Fockens P, Stalmeier PFM, ten Kate FJW, van Dekken H, Obertop H, Tilanus HW, van Lanschot JJB: Extended transthoracic resection compared with limited transhiatal resection for adenocarcinoma of the esophagus. N Engl J Med 2002;347:1662-1669.

14 Bunt TMG, Bonenkamp JJ, Hermans J, van de Velde CJH, Arends JW, Fleuren G, Bruijn JA: Factors influencing noncompliance and contamination in a randomized trial of 'Western' (R1) versus 'Japanese' (R2) type surgery in gastric cancer. Cancer 1994;73: 1544-1551.

15 Degiuli M, Sasako M, Ponti A, Calvo F: Survival results of a multicenter phase II study to evaluate $\mathrm{D} 2$ gastrectomy for gastric cancer. Br J Cancer 2004;90:1727-1732.

16 Wu CW, Hsiung CA, Lo SS, Hsieh MC, Chen JH, Li AFY, Lui WY, Peng JW: Nodal dissection for patients with gastric cancer: a randomised controlled trial. Lancet Oncol 2006; 7:309-315.

17 Japanese Gastric Cancer Association: Japanese Classification of Gastric Carcinoma, ed 1. Tokyo, Kanahara, 1995, p 15.
18 Macdonald JS, Smalley SR, Benedetti J, Este SANC, Stemmermann NG, Haller DG, Ajani JA, Gunderson LL, Jessup JM, Martenson JA: Chemoradiotherapy after surgery compared with surgery alone for adenocarcinoma of the stomach or gastroesophageal junction. $\mathrm{N}$ Engl J Med 2001;345:725-730.

19 Macdonald JS: Postoperative combined radiation and chemotherapy improves disease-free survival (DFS) and overall survival (OS) in resected adenocarcinoma of the stomach and gastroesophageal junction: update of the results of Intergroup Study INT0116 (SWOG 9008). Virtual Meeting of ASCO GI Symposium.

20 Hundahl SA, Macdonald JS, Benedetti J, Fitzsimmons T: Surgical treatment variation in a prospective, randomized trial of chemoradiotherapy in gastric cancer: the effect of undertreatment. Ann Surg Oncol 2002;9: 278-286.

21 Miyashiro I, Furukawa H, Sasako M, Yamamoto S, Nashimoto A, Nakajima T, Kinoshita T, Kobayashi O, Arai K; Gastric Cancer Surgical Study Group of the Japan Clinical Oncology Group: No survival benefit with adjuvant chemotherapy for serosa-positive gastric cancer (JCOG9206-2). Proc 2005 Gastrointestinal Cancer Symp, p 84.

22 Hulscher JBF, van Lanschot JJ: Individualised surgical treatment of patients with an adenocarcinoma of the distal oesophagus or gastro-oesophageal junction. Dig Surg 2005; 22:130-134.

-23 Sasako M, Sano T, Yamamoto S, Sairenji M, Arai K, Kinoshita T, Nashimoto A, Hiratsuka M: Left thoracoabdominal approach versus abdominal-transhiatal approach for gastric cancer of the cardia or subcardia: a randomised controlled trial. Lancet Oncol 2006;7:644-651. 